\title{
Exclusive Breastfeeding Practice and Associated Factors among Mothers Attending Private Pediatric and Child Clinics, Addis Ababa, Ethiopia: A Cross-Sectional Study
}

\author{
Laykewold Elyas, ${ }^{1}$ Amha Mekasha, ${ }^{1}$ Amha Admasie, ${ }^{2}$ and Etagegnehu Assefa ${ }^{3}$ \\ ${ }^{1}$ Department of Pediatrics and Child Health, College of Medicine and Health Sciences, Addis Ababa University, Addis Ababa, Ethiopia \\ ${ }^{2}$ School of Public Health, College of Health Sciences and Medicine, Wolaita Sodo University, Wolaita Sodo, Ethiopia \\ ${ }^{3}$ Department of Chemistry, College of Natural and Computational Science, Wolaita Sodo University, Wolaita Sodo, Ethiopia \\ Correspondence should be addressed to Amha Admasie; amhad2002@yahoo.com
}

Received 21 July 2017; Revised 27 October 2017; Accepted 7 November 2017; Published 27 November 2017

Academic Editor: Francesco Porta

Copyright (C) 2017 Laykewold Elyas et al. This is an open access article distributed under the Creative Commons Attribution License, which permits unrestricted use, distribution, and reproduction in any medium, provided the original work is properly cited.

\begin{abstract}
Background. The prevalence of exclusive breastfeeding (EBF) is globally low (35\%) in sub-Saharan Africa, whereas it is 58\% in Ethiopia. Exclusive breastfeeding has the potential to prevent $11.6 \%$ of under-five deaths in developing countries. Therefore, the main objective of this study was to assess the exclusive breastfeeding practice and associated factors on mothers attending private pediatric and child clinics in Addis Ababa, Ethiopia. Methods. An institutional-based cross-sectional study design was used. A total of 380 samples were obtained. Data were collected using a self-administered questionnaire. Data was entered and analyzed using SPSS version 16. Descriptive statistics and logistic regression analysis were used. Results. From 380 mothers, only $44.2 \%$ of the mothers practiced EBF. Two hundred (52.6\%) mothers started breastfeeding within 1 hour of delivery; 161 (42.4\%) of the mothers gave extra food before six months, and 244 (64.2\%) believed that exclusive breastfeeding was sufficient. Moreover, 288 (75.8\%) mothers breastfed their children eight or more times per day. Spontaneous vaginal delivery was a significant factor to practice EBF (AOR: 1.86, 95\% CI: 1.19-2.89). Conclusion. EBF practice in this study was low. Spontaneous vaginal delivery was a significant factor for EBF; hence, it is very crucial to promote EBF.
\end{abstract}

\section{Background}

Exclusive breastfeeding (EBF) has been defined by the WHO as the situation where "the infant has received only breast milk from his/her mother or a wet nurse, or expressed breast milk and no other liquids, or solids, with the exception of drops or syrups consisting of vitamins, minerals, supplements, or medicines" [1]. Breastfeeding is a natural food that serves as a complete source of infant nutrition for the first six months of life. It contains all the necessary nutrients provided in a bioavailable and easily digestible form, protecting both mothers and children against illnesses and diseases with immunological properties [2]. Breast milk contains essential fatty acids needed for the infant's growing brain, eyes, and blood vessels and these are not available in other types of milk. Breastfeeding on demand at day and night at least 8 times in 24 hours will provide more milk as suckling stimulates milk production [3]. Infants that are exclusively breastfed have a lower chance of becoming ill or dying from diarrhea and infections and are less likely to acquire pneumonia, meningitis, and ear infections than those that were not exclusively breastfed [4]; this is protective against single and recurrent incidences of otitis media in particular and the risk of hospitalization for lower respiratory tract infections during the first year of life. In addition, breastfeeding also benefits the society by reducing healthcare costs, parental employee absenteeism, and the associated loss of family income $[5,6]$.

Tampah-Naah and Kumi-Kyereme reported that human breast milk is the healthiest form of milk for human babies with few exceptions, such as when the mother is taking certain drugs or is infected with tuberculosis or HIV [7]. Kong and Lee posited that breast milk is produced under the influence of prolactin and oxytocin; women produce milk after child birth to feed the baby. The initial milk 
produced is often referred to as colostrum, which is rich in immunoglobulins that coat the gastrointestinal tract. This helps protect the newborn until his/her own immune system starts properly functioning and creates a mild laxative effect, expelling meconium and helping to prevent the buildup of bilirubin (a contributory factor in jaundice) [8]. Breastfeeding increases oxytocin levels which also contribute to maternal-child bonding, lowering the risk of developing uterine cancer, osteoporosis, type two diabetes, and breast cancer in women [9].

The World Health Organization (WHO) and UNICEF also recommend that all mothers should breastfeed their children exclusively for the first six months of life $[10,11]$. It is recommended that breastfeeding should begin within one hour after birth. Early initiation of breastfeeding should be promoted and prelacteal feeds should be discouraged. Because of its high levels of vitamin A, antibodies, and other protective factors, the colostrum is often considered the baby's first immunization [3]. Simple, valid, and reliable indicators are essential to track the progress and guide investment to improve nutrition and health during the first two years of life. Of the indicators, exclusive breastfeeding ranks first, being estimated to have the potential to prevent $13 \%$ of all deaths [12]. Indeed, of the 6.9 million under-five children that were reported to be dead globally in 2011, an estimated 1 million lives could have been saved by simple and accessible practices such as EBF [12]. Consequently, the WHO and UNICEF (1990) have recommended EBF for six months, followed by introduction of complementary foods and continued breastfeeding for 24 months or more [10]. Despite this initiative, breastfeeding has not reached the desired marks. One major reason often posed for mothers not practicing exclusive breastfeeding is the inability of the nursing mother to lactate sufficiently [13].

Current analyses on global incidence across 140 countries reported an increase in breastfeeding practice in the developing world from 33\% in 1995 to 39\% in 2010 among infants aged 0-5 months and also an improvement from 35\% in 1995 to $47 \%$ in 2010 along with countries in Eastern and Southern Africa [14].

According to the report of Leung and Suave, maternal age was significantly associated with initial BF and showed clear dose-response gradients with older ages [15]. Another study conducted in rural China reported that mothers with education level above senior middle school were less likely to exclusively breastfeed their infants [16].

A study conducted on 10,519 mothers in the US [17] indicated that women with a higher family income level were more likely to exclusively breastfeed their infants than their lower income counterparts. Inversely, studies from Saudi Arabia, Peru, and the Philippines [18] all found that higher family income was associated with a reduced probability of initiation and duration of breastfeeding. In a study on infant feeding practice among nursing personnel in Australia, many women identified employment as a barrier to exclusive breastfeeding practice, and returning to work was one of the reasons why women ceased breastfeeding, with 60 percent of women intending to breastfeed when they return to work, but only 40 percent did so [19].
Nutrition and medical journals have added to the body of research that states simply and emphatically that breast milk's health and developmental benefits far surpass any artificial infant formula [20]. A study in Peru shows that infants under six months of age who were not breastfed had a fourfold greater risk of developing acute respiratory infections compared with exclusively breastfed babies [9].

Low practice of EBF in Ethiopia is attributed to various maternal and child factors, such as having an infant aged 2-3 months, giving birth in a health facility, being a housewife in occupation, receiving counseling/advice on infant and colostrum's feeding, which were contributing factors to practice EBF [21]. Age of the mother and access to postnatal care were also encouraging to practice EBF [22]; mothers who received breastfeeding counseling during pregnancy and being supported by the husband were also motivational factors to practice $\operatorname{EBF}[23,24]$. Better maternal education, marital status, good wealth index, and lower age of the child [25] were more likely to practice exclusive breastfeeding than their counterparts.

According to a study on female medical doctors in Nigeria, only $11 \%$ of mothers practiced exclusive breastfeeding for six months [2]. In many countries including Ethiopia, EBF practice is lower than the international recommendation [26]. Many studies in Ethiopia indicated the different prevalence of EBF in different areas of the country: EDHS 2005, 49\% [27]; EDHS 2011, 52\%, with a mean duration of 4.2 months [28]; Debre Tabor, Amhara Region, Ethiopia, 70.8\% [21]; Enderta, Tigray Region, Ethiopia, 70.2\% [22]; and Motta (East Gojjam), Amhara Region, Ethiopia, 50.1\% [23]. EBF in the last 24 hours preceding the survey in Goba town, Oromia Region, Ethiopia, was 71.3\% [24]. A study done in Gondar, Ethiopia, among female nurses and midwives revealed that $35.9 \%$ practiced EBF for six months, and the mean duration of EBF practice was $4.1 \pm 1.7$ months [29].

Based on a few lines of evidence, EBF practice in Ethiopia is poor, which is contrary to the $\mathrm{WHO}$ recommendations. Most researches on EBF were conducted in regional states of Ethiopia, but none of these studies included women who attended private clinics. Therefore, the purpose of this research was to assess the prevalence and associated factors of EBF practice in private pediatric and child clinics, Addis Ababa, Ethiopia.

\section{Method}

2.1. Study Area and Period. The study area of this research is Addis Ababa which is the capital of Ethiopia. The study was conducted from 1 March to 31 May 2016. There are around 42 hospitals and 21 private clinics in Addis Ababa city. Yeka subcity is one among 10 subcities of Addis Ababa city. The residents of Addis Ababa especially living in Yeka subcity and the surrounding area were the geographic targets covered in the study. Since Yeka subcity and the nearby residents are the frequent customers for the clinic because of the geographical proximity, those who are the users of this clinic service are the direct study population from whom samples have been drawn. 
2.2. Study Design and Population. An institutional-based cross-sectional descriptive study design was used to collect data from mothers who were attending private pediatric and child clinics. The source population were all mothers who were residents of Addis Ababa, who were private clinic users for antenatal care services. The study population were all mothers who were breastfeeding and visited the clinic for different antenatal care services. But mothers who had repeated visits during the study period were excluded from the study.

2.3. Sample Size Determination. The sample size was estimated using a single population proportion formula assuming an expected prevalence for exclusive breastfeeding in Ethiopian demographic and health survey study to be $52 \%$ [28] with a $95 \%$ confidence level, at a $5 \%$ margin of error, adding a nonresponse rate of $10 \%$. The calculated sample size using the above assumptions became 383. By considering a $10 \%$ nonresponse rate, the overall minimum sample size was 421.

2.4. Sampling Techniques and Approach. Not all mothers who were coming to the clinic have been included as part of the study because of logistic feasibility. On average, 600 breastfeeding mothers per month were expected to visit the clinic for antenatal care services. Taking a total of 3 months, 1800 mothers were estimated to visit the clinic. Therefore, a sample was taken from this population within the 3 months' duration. Therefore, data was collected from every five visiting breastfeeding mothers. Based on the exclusion criteria, mothers who came to the clinic more than once during the study period were excluded to avoid repetition for data collection.

2.5. Data Collection Techniques. The data was collected using a self-administered questionnaire to the mothers. For those mothers who are able to read and write, the questionnaire was given to them and they filled it out by themselves freely, but for those mothers who faced difficulties in understanding the questions, they were assisted by the data collectors. The questionnaire was read for them and their response was recorded. The questionnaire was adopted from different literatures so as to suit the local context. The questionnaire was designed with both close-ended and open-ended types of questions.

2.6. Data Analysis Technique. The collected data was cleaned, coded, and entered into EpiData software version 3.1 and then exported to the Statistical Package for the Social Sciences (SPSS) version 16 for Windows for further analysis. Descriptive statistics such as frequencies, proportions, and measures of central tendency and measures of variation were used to describe the distributions of variables. The logistic regression model was used to assess the relation between dependent and explanatory variables. Bivariate analysis was done to examine the associations of single independent variable with exclusive breastfeeding practice.

Independent variables with $P$ value $\leq 0.25$ during bivariate analysis were entered into the multivariate analysis model, for the exclusive breastfeeding practice. Association between dependent and independent variables was assessed using
AOR with 95\% CI. Statistical association was declared significant when the $P$ value was less than 0.05 . Multicollinearity was checked using a cutoff point based on variance inflation factor (VIF) $<10$ and tolerance test $>0.1$. Hosmer and Lemeshew's goodness-of-fit test was used to assess the fitness of the model.

\subsection{Variables}

2.7.1. Dependent Variables. The dependent variable was exclusive breastfeeding practice of mothers who were attending a healthcare service in a private pediatrics and child health clinic in Addis Ababa, Ethiopia.

2.7.2. Independent Variables. Socioeconomic/demographic factors such as child's age and maternal socioeconomic characteristics, knowledge and attitude towards EBF of the mother, knowledge about the importance of EBF, knowledge about extra feed for the children including the time to start, and factors affecting the prevalence of EBF are the main variables addressed in this research.

\subsection{Operational Definition}

2.8.1. Exclusive Breastfeeding. The infant has received only breast milk from his/her mother, or expressed breast milk and no other liquids, or solids, with the exception of drops or syrups consisting of vitamins, minerals supplements, or medicines.

2.9. Ethical Issues. The ethical approval for this study was obtained from the Department of Pediatrics and Child Health, School of Medicine, Addis Ababa University. Mothers have been asked for their consent verbally to confirm their willingness to participate in the study. Prior to enrolling any of the eligible study participants, the purpose, the benefits, and the confidential nature of the study were described and discussed with each participant. Confidentiality was ensured by omitting the names of the respondents from the questionnaire. Only those that consented and proved their willingness to take part in the study were enrolled in the study. Child care and nutritional advice was given to mothers by the data collectors during the data collection period.

\section{Result}

A total of 421 questionnaires were distributed to mothers attending private pediatric clinics. However, 380 questionnaires were found complete for analysis. The remaining 41 of the questionnaires were not fully answered correctly by the respondents.

3.1. Sociodemographic Information about the Respondents. Regarding the profile of the mothers' age distribution, 90 $(23.7 \%)$ of them were in the age group of 15-25 years, whereas $259(68.2 \%)$ of them were in the age group of 26-35 years. The remaining $31(8.2 \%)$ were $36-45$ years of age and above. Majority of the mothers $(349,91.8 \%)$ gave birth 
TABLE 1: Sociodemographic characteristics of mothers attending private pediatric and child clinics, Addis Ababa, Ethiopia, March-May 2016.

\begin{tabular}{|c|c|c|c|}
\hline Variable $(n=380)$ & Respondents' response & Frequency & Percent \\
\hline \multirow{3}{*}{ Age of mother } & $15-25$ years & 90 & 23.7 \\
\hline & $26-35$ years & 259 & 68.2 \\
\hline & $36-45$ years and above & 31 & 8.2 \\
\hline \multirow{4}{*}{ Religion of mother } & Orthodox & 293 & 77.1 \\
\hline & Muslim & 26 & 6.8 \\
\hline & Protestant & 55 & 14.5 \\
\hline & Other & 6 & 1.6 \\
\hline \multirow{5}{*}{ Educational status of mother } & Literate & 14 & 3.7 \\
\hline & Primary to secondary school & 108 & 28.4 \\
\hline & Diploma & 131 & 34.5 \\
\hline & First degree & 106 & 27.9 \\
\hline & Masters and above & 21 & 5.5 \\
\hline \multirow{2}{*}{ Parental employment status } & Employed & 218 & 57.4 \\
\hline & Unemployed & 162 & 42.6 \\
\hline \multirow{3}{*}{ Marital status } & Married & 362 & 95.3 \\
\hline & Unmarried & 13 & 3.4 \\
\hline & Divorced/widowed & 5 & 1.3 \\
\hline \multirow{2}{*}{ Means of household income } & I have my own income & 170 & 44.7 \\
\hline & Only my husband's income & 210 & 55.3 \\
\hline \multirow{3}{*}{ Amount of monthly income } & 7001-11000 ETB* & 74 & 19.5 \\
\hline & 11001-15000 ЕТВ & 145 & 38.2 \\
\hline & $>15000$ ETB & 161 & 42.4 \\
\hline
\end{tabular}

${ }^{*}$ ETB: Ethiopian Birr.

when they were below the age of 36 . Regarding the religion of mothers, $293(77.1 \%), 55(14.5 \%)$, and $26(6.8 \%)$ were Orthodox Christians, Protestants, and Muslims, respectively.

Regarding mothers' education status, it was also found that $14(3.7 \%)$ were able to read and write, $108(28.4 \%)$ completed either primary or secondary school, 131 (34.5\%) had a diploma level of education, and 127 (33.4\%) had a degree and were masters graduates.

In terms of the means of income for the mothers, 210 (55.3\%) were living with the income of their husbands, whereas the rest $(170,44.7 \%)$ had their own means of income, which means they were either employed or had their personal business. The amount of monthly income ranges from a minimum of 7000.00 ETB to more than 15000.00 ETB. $161(42.4 \%)$ of the mothers had a monthly income above $15000.00 \mathrm{ETB}$, whereas 145 (38.2\%) had a monthly income of 11000.00-15000.00 ETB (Table 1).

3.2. Child Profile. The age distributions of female and male children were more or less equal, 195 (51.3\%) females and 185 (48.7\%) males, but the females' proportion was a bit more than the males'. Regarding the age of the child, $262(68.9 \%)$ of the children were aged between 7 and 24 months, whereas 64 (16.8\%) of the children were 3 months of age or less. Almost all mothers $(377,99.2 \%)$ gave birth in health institutions like hospitals, health centers, and specialized clinics, while the rest of them gave birth at home. As it is a big city with a relatively civilized community, it is not tolerable for a mother to give birth at home in a normal circumstance (Table 2).
TABLE 2: Child profile of mothers attending private pediatric clinics, Addis Ababa, Ethiopia, March-May 2016.

\begin{tabular}{lcc}
\hline $\begin{array}{l}\text { Variable with respondents' response } \\
(n=380)\end{array}$ & Frequency & Percent \\
\hline $\begin{array}{l}\text { Sex of the child } \\
\quad \text { Female }\end{array}$ & 195 & 51.3 \\
$\quad$ Male & 185 & 48.7 \\
Age of the child & & \\
$\quad \leq 3$ months & 64 & 16.8 \\
$\quad 4-6$ months & 54 & 14.2 \\
7-24 months & 262 & 68.9 \\
Birth place of the child & & \\
$\quad$ Home & 3 & 0.8 \\
$\quad$ Health institution & 377 & 99.2 \\
\hline
\end{tabular}

3.3. Exclusive Breastfeeding, Complimentary Feeding, and Prenatal Status. Among mothers performing the exclusive breastfeeding practice, 168 (44.2\%) had EBF for 6 months or more, while $212(55.8 \%)$ provided EBF before 6 months of age. Two hundred (52.6\%) mothers started to breastfeed within 1 hour of delivery; the rest $(114,30 \%)$ started breastfeeding after 1 hour of delivery. Hence, children from these mothers $(114,30 \%)$ are assumed to have a lack of important elements obtained from their mothers' breast milk because of the delay in starting breastfeeding. Vitamin A, antibodies, and other protective factors are highly important for the 
children, but the mothers do not have this awareness. Sixtysix (17.4\%) mothers even did not remember when they started breastfeeding. Some mothers indicated that the child was not willing to start breastfeeding right after delivery.

Concerning the mode of delivery of the mothers, 193 (50.8\%) delivered by SVD and the rest $(187,49.2 \%)$ gave birth by C/S.

Regarding extra foods, 161 (42.4\%) of the respondents gave extra food for their child before six months. Two hundred forty-four (64.2\%) mothers in this study knew that EBF was sufficient for their child, while the rest (136, 35.8\%) believed that EBF was not sufficient for their child. Moreover, $288(75.8 \%)$ mothers breastfed their child 8 or more times per day (Table 3).

3.4. Bivariate and Multivariate Logistic Regression. Numerous predictors of exclusive breastfeeding practice before six months in under-five children were assessed using logistic regression model. Each potential predictor variable was analyzed using binary logistic regression, and hence the age of the child and mother, religion of the mother, means of income of the mother, mode of delivery, experience of fluid giving before six months, and thinking that EBF is sufficient for six months were shown to have a significant association with the dependent variable $(P<0.25)$. Furthermore, significantly associated variables were entered to the multivariate logistic regression model using Enter method of regression. As a result of multivariate logistic regression, only the mode of delivery was shown to have a significant association with the exclusive breastfeeding practice at $P<0.05$ (Table 4).

\section{Discussion}

Based on the study, the prevalence of exclusive breastfeeding practice was 168 (44.2\%); this was lower than the value by Ethiopian Demographic and Health Surveys 2005, which was $49 \%$ [27], EDHS 2011 which was $52 \%$ with a median duration of 2.3 months and mean duration of 4.2 months [28], EDHS 2016 which was 58\% [30], and Motta (East Gojjam), Amhara Region, Ethiopia, which was 50.1\% [23]. But this value was by far lower than those in studies in Enderta, Tigray Region, Ethiopia, 70.2\% [22]; Debre Tabor town, Amhara Region, Ethiopia, 70.8\% [21]; and EBF in the last 24 hours preceding the survey in Goba town, Oromia Region, Ethiopia, 71.3\% [24]. The difference could be due to the difference in health information and awareness. The World Health Organization (WHO) and the United Nations Children's Fund (UNICEF) recommend that all mothers should breastfeed their children exclusively for the first 6 months and thereafter they should continue to breastfeed for as long as the mother and child wish, and both appropriate and sufficient weaning food should be added after six months of life [16]; the WHO Global and National Infant and Young Child Feeding guidelines recommend that all newborns should be exclusively breastfed for the first six months [16].

$52.6 \%$ of the mothers started breastfeeding their newborn child within 1 hour. The rest (30\%) started breastfeeding after 1 hour. Even $17.4 \%$ of the study population did not remember when they started breastfeeding. The WHO and
UNICEF recommend that all mothers should breastfeed their children exclusively for the first six months of life. It is also recommended that breastfeeding should begin within one hour after birth. Early initiation of breastfeeding should be promoted and prelacteal feeds should be discouraged. Because of its high levels of vitamin A, antibodies, and other protective factors, the colostrum is often considered as the baby's first immunization [16]. This study has insignificant differences with other studies regarding the initiation of breastfeeding within one hour: Debre Tabor town, Amhara Region, Ethiopia, 78.6\% [21], Enderta (woreda), Tigray Region, Ethiopia, 65\% [22]. Hence, children of these mothers (30\%) who initiated breastfeeding after 1 hour missed the important elements to be obtained from the mothers' milk because of the delay in starting breastfeeding. Of course, the cause of the delay in initiation of breastfeeding was not only the mothers' lack of awareness but also the fact that some mothers believed that the child was not willing to start breastfeeding right after delivery.

The median duration of EBF in the study area was found to be 0.8 months, which is comparable to EDHS 2011 where the median duration for Afar Region of Ethiopia was 0.6 months. This result is very low compared to many regions with a median ranging from 1 month (Addis Ababa) to 4.6 months (Amhara Region) [28], also lower as compared to Addis Ababa, 2.9 months of median duration [30]. This result is an alarm necessitating a significant effort from the responsible bodies on the problem.

Regarding the impact of knowledge of the mothers on whether they should feed their child extra fluid before six months, although their knowledge is generally good about the importance of EBF, they did not practice it to the required level. As discussed before, knowing the importance is not sufficient. Since other factors like employment and parity affect the prevalence of EBF, mothers do not follow the recommended EBF guidelines recommended by the WHO and UNICEF. Employed mothers have a lower opportunity to stay at home, compromising exclusive breastfeeding. Mothers also may have to leave their babies to search for a job. It was found that only $43 \%$ of employed mothers breastfed their child for six months, whereas the unemployed figure is $56 \%$, which is $13 \%$ more than the employed figure. The workload that employed mothers have affects the prevalence of EBF.

Unfortunately, most factors which are known to be a contributing factor in other studies were not significantly associated with EBF in this study. But only delivery type has a significant influence on the EBF; a mother who delivered by SVD is 1.86 times more likely to practice exclusive breastfeeding than the mother who had a C/S delivery (AOR: 1.86, 95\% CI: 1.19-2.89). This study was consistent with the study done by Tewabe et al. (mothers that delivered by SVD were 2.06 times more likely to practice EBF than those that delivered by C/S [23]) and Setegn et al. (mothers that delivered by SVD were 1.7 times more likely to practice EBF than those that delivered by C/S [24]). But this study was contradicting with the study where a mother who delivered by SVD was 0.48 times less likely to practice exclusive breastfeeding than a mother who had a C/S delivery [21]. Delivery type (i.e., whether spontaneous or by Cesarean section) has been 
TABLE 3: Mothers' experience of breastfeeding and giving supplementary foods practice of mothers attending private pediatric clinics, Addis Ababa, Ethiopia, March-May 2016.

\begin{tabular}{|c|c|c|}
\hline Variables with respondents' response $(n=380)$ & Frequency & Percent \\
\hline \multicolumn{3}{|l|}{ How long have you provided only breastfeeding? } \\
\hline$\geq 6$ months & 168 & 44.2 \\
\hline$<6$ months & 212 & 55.8 \\
\hline \multicolumn{3}{|l|}{$\begin{array}{l}\text { Have you given any fluid before six months besides } \\
\text { breastfeeding? }\end{array}$} \\
\hline Yes & 161 & 42.4 \\
\hline No & 219 & 57.6 \\
\hline \multicolumn{3}{|l|}{ Parental delivery system } \\
\hline SVD & 193 & 50.8 \\
\hline $\mathrm{C} / \mathrm{S}$ & 187 & 49.2 \\
\hline \multicolumn{3}{|l|}{ Parity status of mothers } \\
\hline 1st & 203 & 53.4 \\
\hline 2nd & 107 & 28.2 \\
\hline $3 \mathrm{rd}$ & 49 & 12.9 \\
\hline 4 th & 17 & 4.5 \\
\hline 5 th & 4 & 1.1 \\
\hline \multicolumn{3}{|l|}{ When was breastfeeding started? } \\
\hline Within 1 hour & 200 & 52.6 \\
\hline After 1 hour & 114 & 30.0 \\
\hline I do not remember & 66 & 17.4 \\
\hline \multicolumn{3}{|l|}{$\begin{array}{l}\text { Have you given any fluid before six months besides } \\
\text { breastfeeding? }\end{array}$} \\
\hline Yes & 161 & 42.4 \\
\hline No & 219 & 57.6 \\
\hline \multicolumn{3}{|c|}{$\begin{array}{l}\text { Do you think that EBF is sufficient for your child for the } \\
\text { first } 6 \text { months? }\end{array}$} \\
\hline Yes & 244 & 64.2 \\
\hline No & 136 & 35.8 \\
\hline \multicolumn{3}{|c|}{$\begin{array}{l}\text { I think that my child will face a health problem if only } \\
\text { EBF is given for long }\end{array}$} \\
\hline Yes & 249 & 65.5 \\
\hline No & 131 & 34.5 \\
\hline \multicolumn{3}{|l|}{ How many times a day do you breastfeed your child? } \\
\hline 6 times per day & 31 & 8.2 \\
\hline 7 times per day & 17 & 4.5 \\
\hline 8 times per day & 44 & 11.6 \\
\hline$>8$ times per day & 288 & 75.8 \\
\hline \multicolumn{3}{|c|}{$\begin{array}{l}\text { I think that my child will face a health problem if only } \\
\text { EBF is given for long }\end{array}$} \\
\hline Yes & 249 & 65.5 \\
\hline No & 131 & 34.5 \\
\hline \multicolumn{3}{|c|}{$\begin{array}{l}\text { Do you think that breastfeeding for long is important } \\
\text { for the health and strength of the child? }\end{array}$} \\
\hline Yes & 375 & 98.7 \\
\hline No & 5 & 1.3 \\
\hline
\end{tabular}


TABLE 4: Bivariate and multivariate logistic regression of factors affecting EBF of mothers attending private pediatric clinics, Addis Ababa, Ethiopia, March-May 2016.

\begin{tabular}{|c|c|c|c|c|}
\hline & \multicolumn{2}{|c|}{ EBF practice } & \multirow{2}{*}{$\begin{array}{c}\text { COR } \\
(95 \% \mathrm{CI})\end{array}$} & \multirow{2}{*}{$\begin{array}{c}\mathrm{AOR} \\
(95 \% \mathrm{CI})\end{array}$} \\
\hline & Yes & No & & \\
\hline \multicolumn{5}{|l|}{ Age of child } \\
\hline$\leq 3$ months & 26 & 38 & $0.85(0.49-1.48)$ & $0.84(0.47-1.49)$ \\
\hline 4 months & 14 & 10 & $1.74(0.74-4.05)$ & $1.76(0.72-4.30)$ \\
\hline 5 months & 2 & 11 & $0.23(0.05-1.04)$ & $0.17(0.03-0.80)^{*}$ \\
\hline 6 months & 9 & 8 & $1.39(0.52-3.73)$ & $1.38(0.49-3.85)$ \\
\hline 7-24 months & 117 & 145 & 1.00 & 1.00 \\
\hline \multicolumn{5}{|l|}{ Age of mother } \\
\hline 15-25 years & 34 & 56 & $1.10(0.47-2.58)$ & $0.79(0.32-1.94)$ \\
\hline $26-35$ years & 123 & 136 & $1.64(0.76-3.57)$ & $1.60(0.71-3.59)$ \\
\hline $36+$ years & 11 & 20 & 1.00 & 1.00 \\
\hline \multicolumn{5}{|l|}{ Religion of mother } \\
\hline Orthodox & 121 & 172 & $0.70(0.14-3.54)$ & $0.70(0.13-3.69)$ \\
\hline Muslim & 18 & 8 & $2.25(0.37-13.67)$ & $1.97(0.30-12.83)$ \\
\hline Protestant & 26 & 29 & $0.90(0.17-4.84)$ & $1.08(0.19-6.07)$ \\
\hline Other & 3 & 3 & 1.00 & 1.00 \\
\hline \multicolumn{5}{|c|}{ Do mothers have their own means of income? } \\
\hline My own income & 69 & 101 & $0.77(0.51-1.15)$ & $0.74(0.48-1.16)$ \\
\hline With my husband & 99 & 111 & 1.00 & 1.00 \\
\hline \multicolumn{5}{|l|}{ Mode of delivery } \\
\hline SVD & 97 & 96 & $1.65(1.10-2.48)$ & $1.86(1.19-2.89)^{*}$ \\
\hline $\mathrm{C} / \mathrm{S}$ & 71 & 116 & 1.00 & 1.00 \\
\hline \multicolumn{5}{|c|}{$\begin{array}{l}\text { Have you given any fluid before six months } \\
\text { besides breastfeeding? }\end{array}$} \\
\hline Yes & 64 & 97 & $0.73(0.48-1.10)$ & $0.77(0.50-1.20)$ \\
\hline No & 104 & 115 & 1.00 & 1.00 \\
\hline \multicolumn{5}{|c|}{$\begin{array}{l}\text { Do you think that EBF is sufficient for your child } \\
\text { for the first } 6 \text { months? }\end{array}$} \\
\hline Yes & 115 & 129 & $0.72(0.47-1.10)$ & $0.77(0.49-1.21)$ \\
\hline No & 53 & 83 & 1.00 & 1.00 \\
\hline
\end{tabular}

${ }^{*}$ Significance at $P<0.05$.

found to influence both EBF initiation and duration. While one group of researchers have reported positive associations between delivery type (vaginal delivery) and EBF, others have found an inverse association. In Western Australia, it was found that mothers who had a vaginal delivery were about twice as likely to exclusively breastfeed at hospital discharge compared to mothers who had Cesarean delivery [19]. The reason could be that the mother who had a C/S delivery was less comfortable and felt fatigued after the $\mathrm{C} / \mathrm{S}$ procedure to give her breast to her newborn.

\section{Conclusion}

Exclusive breastfeeding (EBF) practice in this study was lower than in most of the studies. Mode of delivery (spontaneous vaginal delivery) was indicated as the determinant factor for exclusive breastfeeding practice of mothers.

\section{Additional Points}

Recommendation. It is so crucial that EBF has to be promoted a lot. For this realization, the Federal Ministry of Health of Ethiopia, local and international NGOs working on health areas, and health institutions should play their role to enhance exclusive breastfeeding practice of mothers with training during antenatal and postnatal visits for women. Health personnel who are working in the clinics should advise mothers to have a spontaneous vaginal delivery and should not insist on performing C/S delivery unless and otherwise medically justified. Limitations of the Study. This study was conducted in a single private pediatric and child clinic, which could lead to less plausible generalization and can be considered as the main limitation of the study. Besides, recall bias and social desirability bias were critical manifestations in self-reported responses. 


\section{Conflicts of Interest}

The authors declare that they have no conflicts of interest.

\section{Authors' Contributions}

Laykewold Elyas and Amha Mekasha were involved in the study protocol design and development. Laykewold Elyas and Amha Admasie were involved in study development. Laykewold Elyas was involved in data collection. Laykewold Elyas and Amha Admasie were involved in data analysis. Amha Admasie prepared the manuscript and Laykewold Elyas edited it. Amha Mekasha supervised and monitored the protocol. All authors read and approved the final manuscript.

\section{Acknowledgments}

The authors are honored to acknowledge and express their sincere thanks to Addis Ababa University for the financial support to conduct this research. They are also very grateful to work with the humble data collectors and thank them a lot for all their contributions. Many thanks and respect are extended to Dr. Zewdu Tilahun and his wife, Hiwot Ibrahim, for supporting this work throughout the data collection.

\section{References}

[1] World Health Organization. Indicators for assessing breastfeeding practices. Report of an informal meeting. Geneva, Switzerland: 1991.

[2] L. Salami, "Factors influencing breastfeeding practices in Edo state, Nigeria," African Journal of Food, Agriculture, Nutrition and Development, vol. 6, no. 2, 2011.

[3] T. Lavender, C. McFadden, and L. Baker, "Breastfeeding and family life," Maternal \& Child Nutrition, vol. 2, no. 3, pp. 145155, 2006.

[4] A. McFadden and G. Toole, "Exploring women's views of breastfeeding: a focus group study within an area with high levels of socio-economic deprivation," Maternal \& Child Nutrition, vol. 2, no. 3, pp. 156-168, 2006.

[5] T. M. Ball and D. M. Bennett, "The economic impact of breastfeeding," Pediatric Clinics of North America, vol. 48, no. 1, pp. 253-262, 2001.

[6] J. M. Jones, "The methodology of nutritional screening and assessment tools," Journal of Human Nutrition and Dietetics, vol. 15, no. 1, pp. 59-71, 2002.

[7] A. M. Tampah-Naah and A. Kumi-Kyereme, "Determinants of exclusive breastfeeding among mothers in ghana: a crosssectional study," International Breastfeeding Journal, vol. 8, no. 1, article no. 13, 2013.

[8] S. K. F. Kong and D. T. F. Lee, "Factors influencing decision to breastfeed," Journal of Advanced Nursing, vol. 46, no. 4, pp. 369379, 2004.

[9] I. Kull, M. Wickman, G. Lilja, S. L. Nordvall, and G. Pershagen, "Breast feeding and allergic diseases in infants-a prospective birth cohort study," Archives of Disease in Childhood, vol. 87, no. 6, pp. 478-481, 2002.

[10] World Health Organization. Innocent declaration on the protection, promotion and support of breastfeeding. Geneva, Switzerland: 1990.
[11] World Health Organization. World Health Organization: 10 facts on child health. Geneva, Switzerland: World Health Organization; 2012.

[12] Collaborative Group on Hormonal Factors in Breast Cancer, "Breast cancer and breastfeeding: collaborative reanalysis of individual data from 47 epidemiological studies in 30 countries, including 50302 women with breast cancer and 96973 women without the disease," The Lancet, vol. 360, no. 9328, pp. 187-195, 2002.

[13] M. Tafesse, "Challenge of exclusive breast feeding among female nurses and mid-wives in government and private hospitals of Addis Ababa," Journal of Food and Nutrition Sciences, vol. 3, no. 5, pp. 174-179, 2015.

[14] X. Cai, T. Wardlaw, and D. W. Brown, "Global trends in exclusive breastfeeding," International Breastfeeding Journal, vol. 7, article no. 12, 2012.

[15] A. K. Leung and R. S. Suave, "Breast is the best for babies," Journal of the National Medical Association, vol. 97, no. 7, pp. 1010-9-1019, 2005.

[16] World Health Organization. World Health Organization: fiftyfifth world health assembly, provisional agenda item 13.10 Infant and young child nutrition Global strategy on infant and young child feeding, Report by the Secretariat. Geneva, Switzerland: 2002.

[17] US department of Health and Human Services. The surgeon Generals call for Action to Support Breast Feeding. In: Health and Human Services office of the surgeon, editor. Washington, D.C, USA, 2011.

[18] UNICEF. Improving Exclusive Breastfeeding Practice by Using Communication for Development in Infant and Young Child Feeding Programs, United Nations Children's Fund. 2010.

[19] D. Weber, A. Janson, M. Nolan, L. M. Wen, and C. Rissel, "Female employees' perceptions of organisational support for breastfeeding at work: findings from an Australian health service workplace," International Breastfeeding Journal, vol. 6, article no. 19, 2011.

[20] P. Chatterji and J. Brooks-Gunn, "WIC participation, breastfeeding practices, and well-child care among unmarried, lowincome mothers," American Journal of Public Health, vol. 94, no. 8, pp. 1324-1327, 2004.

[21] G. Arage and H. Gedamu, "Exclusive breastfeeding practice and its associated factors among mothers of infants less than six months of age in debre tabor town, northwest ethiopia: a crosssectional study," Advances in Public Health, vol. 2016, pp. 1-7, 2016.

[22] B. Teka, H. Assefa, and K. Haileslassie, "Prevalence and determinant factors of exclusive breastfeeding practices among mothers in Enderta woreda, Tigray, North Ethiopia: A cross-sectional study," International Breastfeeding Journal, vol. 10, no. 1, article no. 2, 2015.

[23] T. Tewabe, A. Mandesh, T. Gualu, G. Alem, G. Mekuria, and H. Zeleke, "Exclusive breastfeeding practice and associated factors among mothers in Motta town, East Gojjam zone, Amhara Regional State, Ethiopia, 2015: A cross-sectional study," International Breastfeeding Journal, vol. 12, no. 1, article no. 12, 2017.

[24] T. Setegn, T. Belachew, M. Gerbaba, K. Deribe, A. Deribew, and S. Biadgilign, "Factors associated with exclusive breastfeeding practices among mothers in Goba district, south east Ethiopia: a cross-sectional study," International Breastfeeding Journal, vol. 7, article 17, pp. 1-8, 2012. 
[25] T. Alemayehu, J. Haidar, and D. Habte, "Determinants of exclusive breastfeeding practices in Ethiopia," Ethiopian Journal of Health Development, vol. 23, no. 1, 2009.

[26] Y. Berhane, D. Haile Mariam, and H. Kloos, "Food and Nutrition," in The Epidemiology and Ecology of Health and Diseases in Ethiopia, J. Haider, H. Kloos, and D. Haile Mariam, Eds., Shama Books, Addis Ababa, Ethiopia, 2006.

[27] CSA. Ethiopia Demographic and Health survey (EDHS) 2005. In: macro CsAaO, editor. Addis Ababa, Ethiopia and Calverton, Maryland USA: Central statistical Agency and ORS macro; 2006.

[28] CSA. Ethiopian demographic and health survey (EDHS) 2011. In: Agency CS, editor. Addis Ababa, Ethiopia: Central Statistical Agency [Ethiopia] and ICF International; 2012.

[29] B. A. Dachew and B. B. Bifftu, "Breastfeeding practice and associated factors among female nurses and midwives at North Gondar Zone, Northwest Ethiopia: A cross-sectional institution based study," International Breastfeeding Journal, vol. 9, no. 1, article no. 11, 2014.

[30] CSA. Ethiopian demographic and health survey (EDHS) 2016. In: Agency CS, editor. Addis Ababa, Ethiopia: Central Statistical Agency [Ethiopia] and ICF International; 2016. 


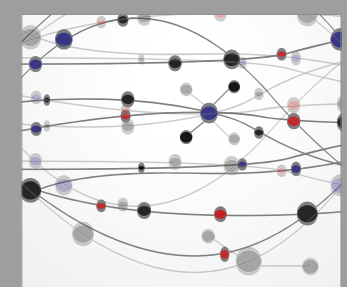

The Scientific World Journal
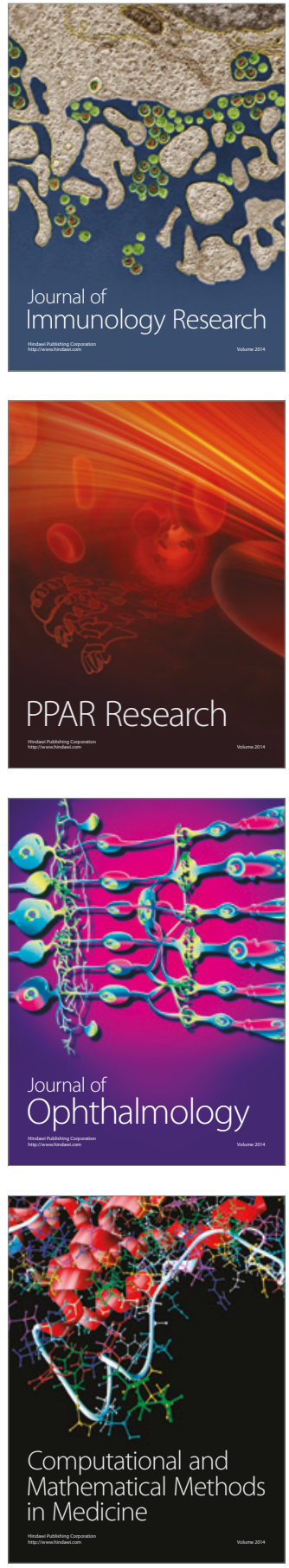

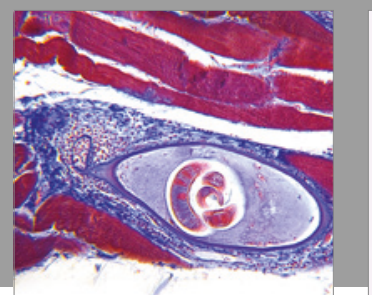

Gastroenterology Research and Practice
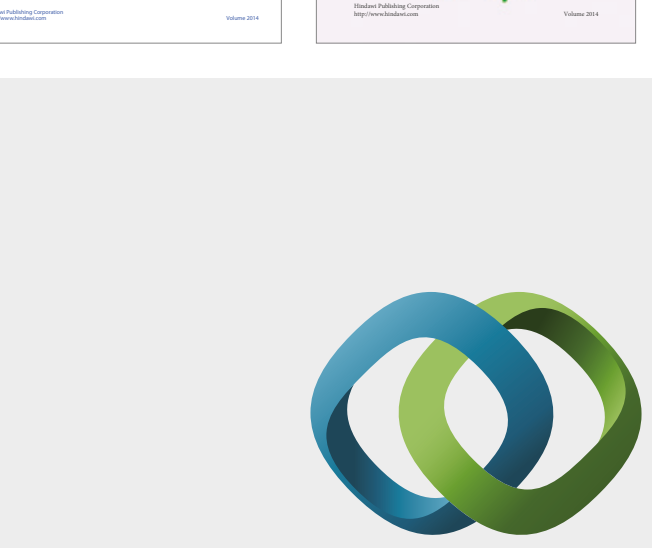

\section{Hindawi}

Submit your manuscripts at

https://www.hindawi.com
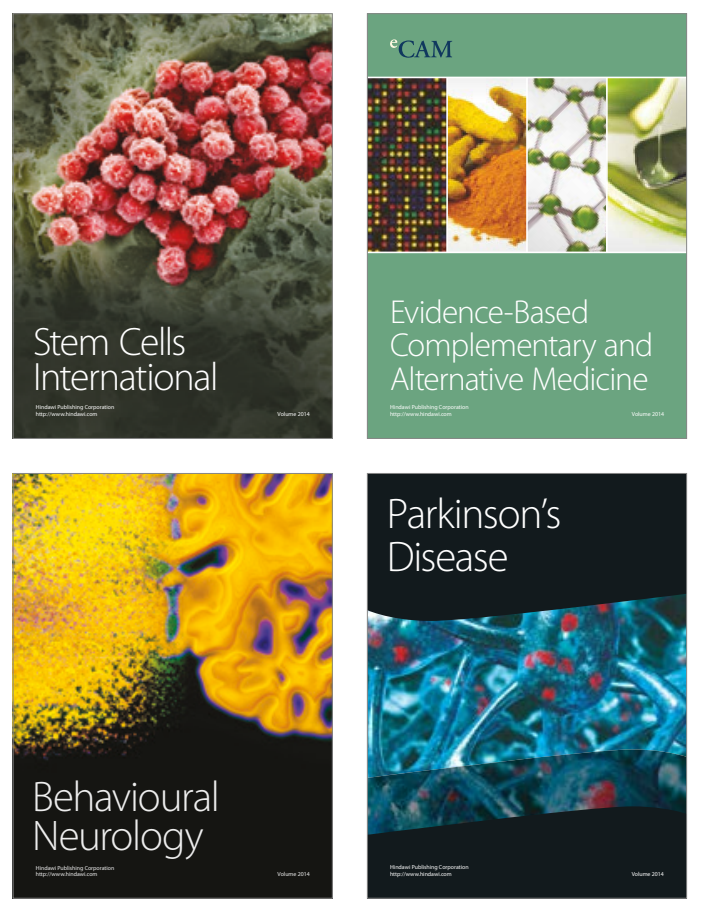
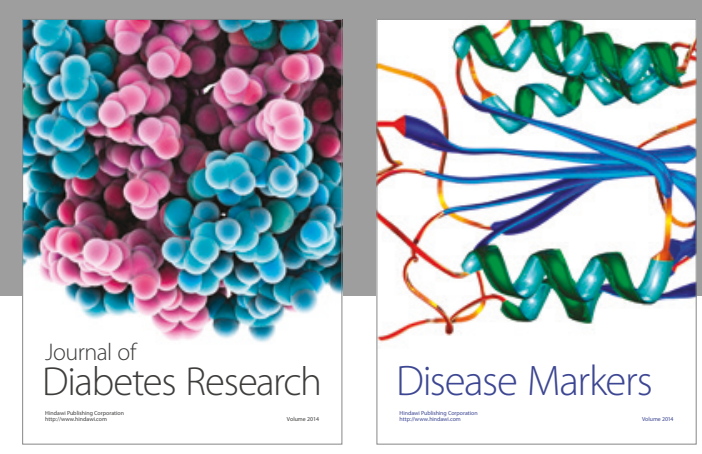

Disease Markers
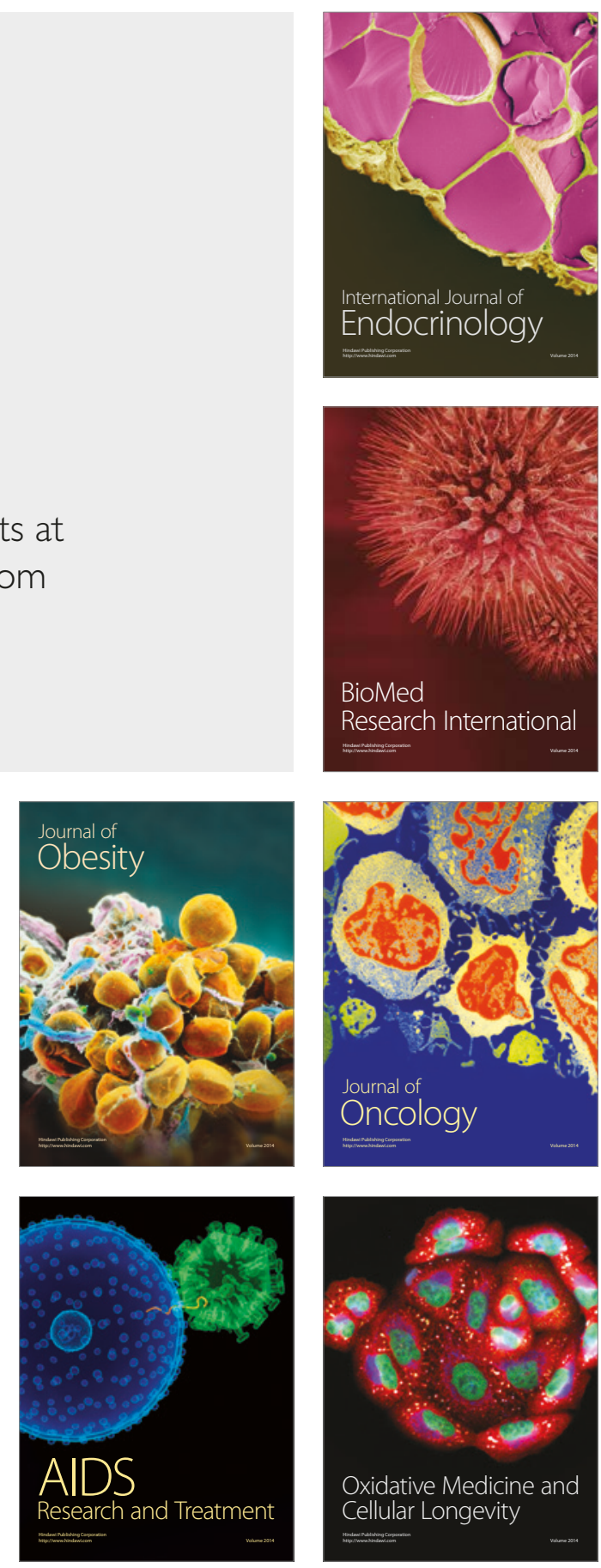